\title{
Rapid Biosynthesis of Silver Nanoparticles Based on Flocculation and Reduction of an Exopolysaccharide from Arthrobacter sp. B4: Its Antimicrobial Activity and Phytotoxicity
}

\author{
Li Yumei, Li Yamei, Li Qiang, and Bao Jie \\ School of Biological Science and Biotechnology, University of Jinan, Shandong, China \\ Correspondence should be addressed to Li Yumei; mls_liym@ujn.edu.cn
}

Received 5 November 2016; Accepted 27 February 2017; Published 3 April 2017

Academic Editor: Jobin Cyriac

Copyright (C) 2017 Li Yumei et al. This is an open access article distributed under the Creative Commons Attribution License, which permits unrestricted use, distribution, and reproduction in any medium, provided the original work is properly cited.

Silver nanoparticles (AgNPs) were rapidly synthesized using an exopolysaccharide from Arthrobacter sp. B4 (B4-EPS). The optimum condition for AgNPs synthesis was under the concentration of $5 \mathrm{~g} / \mathrm{L} \mathrm{B} 4-\mathrm{EPS}$ and $1 \mathrm{mM} \mathrm{AgNO}_{3}$ at $80^{\circ} \mathrm{C}$ between $\mathrm{pH}$ 7.0 and 8.0. The resulting AgNPs displayed a face-centred-cubic structure with the size range from $9 \mathrm{~nm}$ to $72 \mathrm{~nm}$. Further analysis showed that flocculation and reduction of B4-EPS played a pivotal role in the formation of AgNPs. Furthermore, these nanoparticles exhibited great stability, excellent antimicrobial activity, and low phytotoxicity. The aforementioned data provide a feasible and efficient approach for green synthesis of AgNPs using microbial polysaccharides with flocculation and reduction activity, which will be promising in medical filed.

\section{Introduction}

Silver nanoparticles (AgNPs) have been widely used in the field of medicine, food, cosmetics, clothing, chemical conversion, and sensing due to their excellent antimicrobial, catalytic, conductive, and optic properties $[1,2]$. Synthesis of AgNPs via chemical and physical methods has been extensively developed in the last decade. Chemical reduction of silver ions is one of the most common ways to produce AgNPs, which was achieved by some chemical reducing agents such as sodium borohydride, sodium citrate and N,Ndimethyl formamide, and sodium dodecyl sulfate [3-5]. On the other hand, some physical methods including sputter deposition, laser ablation or cluster beam deposition, and thin films have also been exploited to synthesize AgNPs [68]. However, some chemical and physical methods are quite expensive and hazardous, thus the resulting AgNPs have been found to cause potent cytotoxicity [9]. Alternatively, biological materials such as bacteria, fungus, yeasts, actinomycetes, plant leaf or seed, and some biomolecules have been stated as safe to synthesize metal nanoparticles on extra/intercellular level [10-13].
Recently, some natural polysaccharides or their derivatives such as cellulose, chitosan, starch, and sulfated chitosan have been applied to produce nontoxic AgNPs [14-18]. By contrast, microbial polysaccharides have higher reducibility because of their diverse chemical constituents and complex structures. AgNPs have been synthesized by several commercial microbial polysaccharide gums, such as gellan gum and pullulan, which exhibited a strong antimicrobial activity $[19,20]$. In addition, polysaccharide-based bioflocculants from marine Bacillus subtilis MSBN17 and Streptomyces sp. MBRC-91 were also able to contribute to the highperformance production of AgNPs since they easily form a variety of liquid crystals in aqueous solutions [21, 22]. However, the mechanism of AgNP synthesis mediated by flocculated polysaccharide and the bioactivity and toxicity of these nanoparticles were unknown yet.

In our previous study, we discovered that the exopolysaccharide from Arthrobacter sp. B4 (B4-EPS) had high flocculation and reduction activity $[23,24]$. Hence, B4-EPS was used for synthesis of AgNPs in our present work. The relative parameters and the plausible mechanism behind 
the formation of AgNPs were investigated, respectively. The antimicrobial activity and phytotoxicity of these nanoparticles were assayed by a series of experiments.

\section{Materials and Methods}

2.1. Biosynthesis of AgNPs. The cultivation of the strain Arthrobacter sp. B4 and the preparation of B4-EPS were carried out as our previous description [23]. Synthesis of AgNPs was performed using different concentration of B4-EPS $(1,2$, $3,4$, and $5 \mathrm{~g} / \mathrm{L})$, which was mixed with $1 \mathrm{mM}$ silver nitrate $\left(\mathrm{AgNO}_{3}\right)$ solution to produce AgNPs. Different amounts of $\mathrm{AgNO}_{3}(0.5,1,2$, and $3 \mathrm{mM})$ were added to $5 \mathrm{~g} / \mathrm{L}$ of B4EPS solution. The reaction mixtures after homogeneity were incubated at 70,80 , and $90^{\circ} \mathrm{C}$, respectively. The formation of AgNPs was determined by color change and the oxidation of silver ions was confirmed by UV-vis spectra, which was observed in the range of $400-500 \mathrm{~nm}$ [25]. The changes of zeta potential during the process of AgNPs synthesis were measured by Zetasizer 3000HS (Malvern Instruments Ltd., Company, England). The Fourier transform infrared (FTIR) spectra were recorded with a Nicolet IR200FT-IR spectrometer (Thermo Fisher Scientific).

2.2. Characterization of AgNPs. The morphological analysis was performed by a high-resolution transmission electron microscope (HrTEM, JEOL JSM 100CX, Japan) at an accelerating voltage of $200 \mathrm{kV}$. Selected area electron diffraction (SAED) of AgNPs was also analyzed using HrTEM. The energy dispersive X-ray diffraction (EDX) was carried out using the same equipment as HrTEM to confirm the presence of silver element in the NPs. Particle size distribution was calculated for the synthesized nanoparticles using Image J software (http://rsb.info.nih.gov/ij/). The phase composition and crystal structure of the AgNPs were determined by X-ray diffraction (XRD). XRD patterns were collected in the range of $20-80^{\circ} \mathrm{C}(2 \theta)$ operated at $40 \mathrm{kV}$ and $30 \mathrm{~mA}$ (EXPLORER, GNR, Italy).

2.3. Antimicrobial Activity of AgNPs. The antibacterial and antifungal activity of AgNPs were assayed using agar diffusion method [26]. Two typical bacterial strains (Pseudomonas aeruginosa PAO1 and Staphylococcus aureus ATCC25923) and two fungal strains (Candida albicans ATCC 10231 and Fusarium oxysporum ATCC 48112) were used as indicator strains for this analysis. Luria-Bertani medium was used for bacterial cultivation. The fungal strains were grown in potato dextrose medium (F. oxysporum) and Sabouraud Broth Medium (C. albicans), respectively. Different dosages of AgNPs $(20,50$, and $100 \mu \mathrm{L})$ were added to these wells and the zone of inhibition ( $\mathrm{mm}$ ) was measured. B4-EPS, silver nitrate and antibiotics solutions were used as controls. All experiments were performed in triplicate.

2.4. Phytotoxicity of AgNPs. The phytotoxicity assay was performed using alfalfa (Medicago sativa L.) according to a reported method [27]. Briefly, the sterile Whatman filter papers (Ф90) were added to $1 \mathrm{~mL}$ of the AgNPs suspension (three different concentrations). Then the papers were placed in sterile plates, and the alfalfa seeds were placed in each plate. The plates were incubated at $23^{\circ} \mathrm{C}$ for $5 \mathrm{~d}$ with a cycle of light period/dark period $(16 \mathrm{~h} / 8 \mathrm{~h})$. The root length, percentage of seed germination, and content of chlorophyll content were determined as Bettini et al's publication [28]. All the experiments were carried out in triplicate.

\section{Results and Discussion}

3.1. Effects of B4-EPS and $\mathrm{AgNO}_{3}$ Concentration on AgNPs Synthesis. The effect of B4-EPS concentration (1, 2, 3, 4, and $5 \mathrm{~g} / \mathrm{L}$ ) on synthesis of AgNPs was investigated under the condition of $1 \mathrm{mM} \mathrm{AgNO}$ at $70^{\circ} \mathrm{C}$ until the reaction solution turned into dark reddish brown color. The formation of AgNPs was determined via observing the surface plasmon resonance (SPR) bands using UV-vis spectrometer. It seemed that the AgNPs absorbed radiation in the visible regions of 400-500 nm owing to the strong SPR transition [25]. As shown in Figure 1(a), the increased absorption intensity was enhanced with an increase in polysaccharide concentration; the formation of AgNPs was accelerated in higher concentration of B4-EPS owing to the increase of reduction groups. In this case, the blue shift occurred with an absorption shift to lower wavelength at $410 \mathrm{~nm}$, which inferred decrease in the particle size. The said data meant that B4-EPS concentration played an important role in the formation and stabilization of AgNPs. Similarly, the gradual increase in absorption intensity was observed in the AgNPs synthesis by chitosan, pullulan, and $\kappa$-carrageenan polysaccharides $[15,20,29]$. Considering viscosity of B4-EPS, $5 \mathrm{~g} / \mathrm{L}$ of B4-EPS was used to investigate the effect of $\mathrm{AgNO}_{3}$ concentration $(0.5,1,2$, and $3 \mathrm{mM}$ ) on the formation of AgNPs. The absorption intensity of reaction solution reached the maximum value when $1 \mathrm{mM}$ of $\mathrm{AgNO}_{3}$ was used. The aggregation of AgNPs occurred under the condition of high concentration of $\mathrm{AgNO}_{3}(3 \mathrm{mM})$ due to charge attraction between $\mathrm{Ag}^{+}$and $\mathrm{B} 4-\mathrm{EPS} / \mathrm{AgNO}_{3}$ (Figure 1(b)), which was different from other plant polysaccharides in response to $\mathrm{AgNO}_{3}$ concentration during the process of AgNP synthesis [20].

3.2. Effect of $p H$ on AgNP Synthesis. The effect of $\mathrm{pH}$ (4.0, $5.0,6.0,7.0,8.0,9.0$, and 10.0) on synthesis of AgNPs was investigated under the condition of $1 \mathrm{mM}$ AgNO3 and $5 \mathrm{~g} / \mathrm{L}$ B4-EPS at $70^{\circ} \mathrm{C}$ until the reaction solution turned into dark reddish brown color. As shown in Figure 2, no formation of AgNPs was observed below pH 5.0, which might be due to limit reduction of $\mathrm{Ag}^{+}$which was caused by strong electric repulsion between $\mathrm{Ag}^{+}$ions and B4-EPS in acid condition; AgNP synthesis was facilitated in a range of $\mathrm{pH} 7.0$ to 8.0; but no UV-vis absorption bands of AgNPs were observed at a higher $\mathrm{pH}(>8.0)$, which was different from other reports that alkaline condition was in favor of AgNP synthesis [30]. It can be explained that B4-EPS was endowed with high electronegativity in alkaline condition, which was bad for the reduction of $\mathrm{Ag}^{+}$ion due to the existence of amounts of $-\mathrm{COO}^{-}$groups.

3.3. Effects of Temperature and Heating Time on AgNP Synthesis. $1 \mathrm{mM}$ of $\mathrm{AgNO}_{3}$ and $2 \mathrm{~g} / \mathrm{L}$ of B4-EPS were heated 


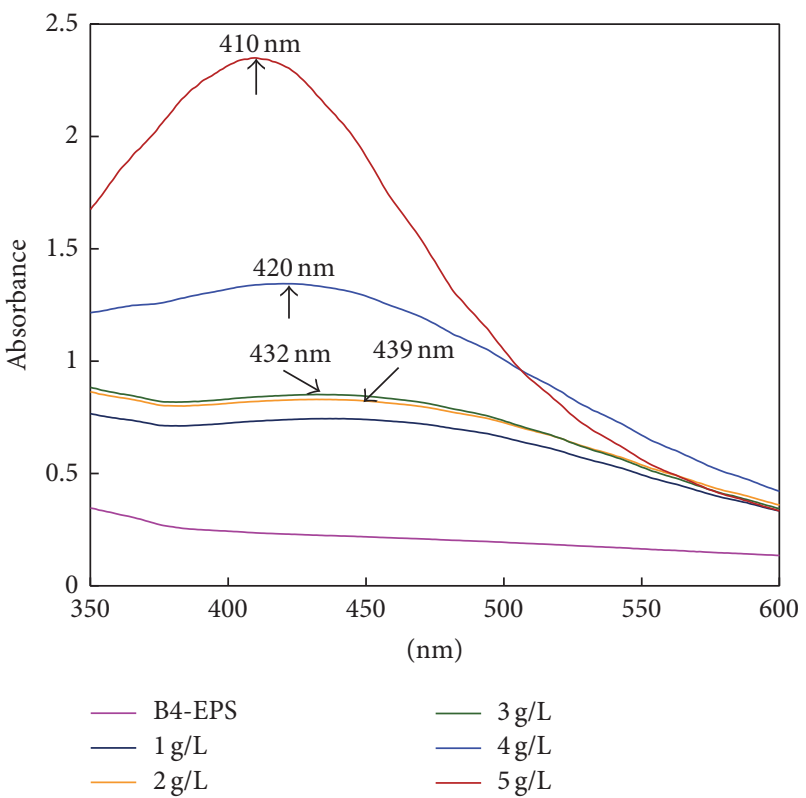

(a)

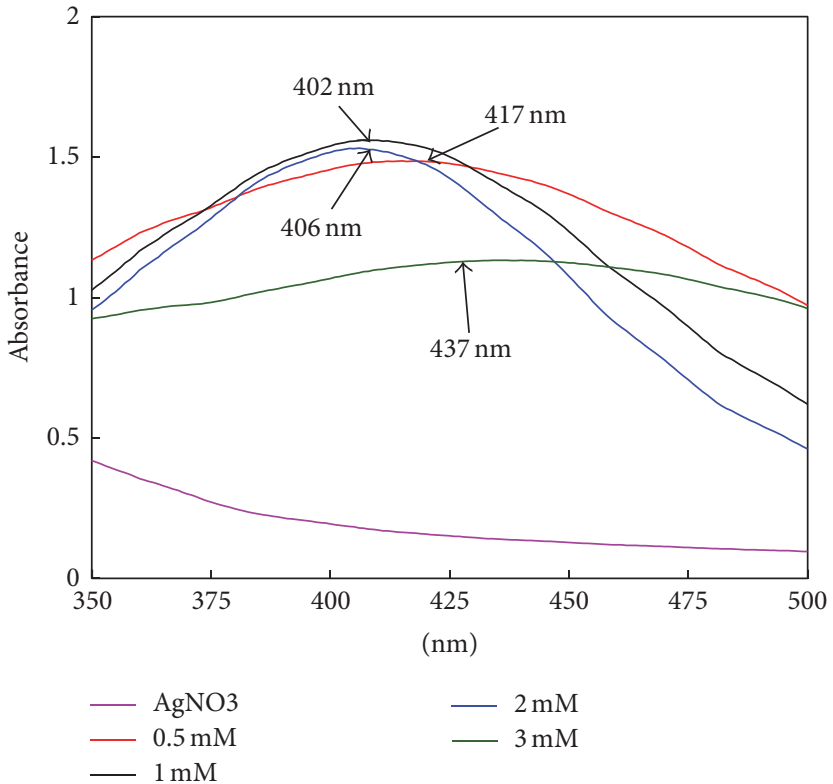

(b)

Figure 1: The effects of B4-EPS (a) and $\mathrm{AgNO}_{3}$ (b) concentration on AgNP synthesis.

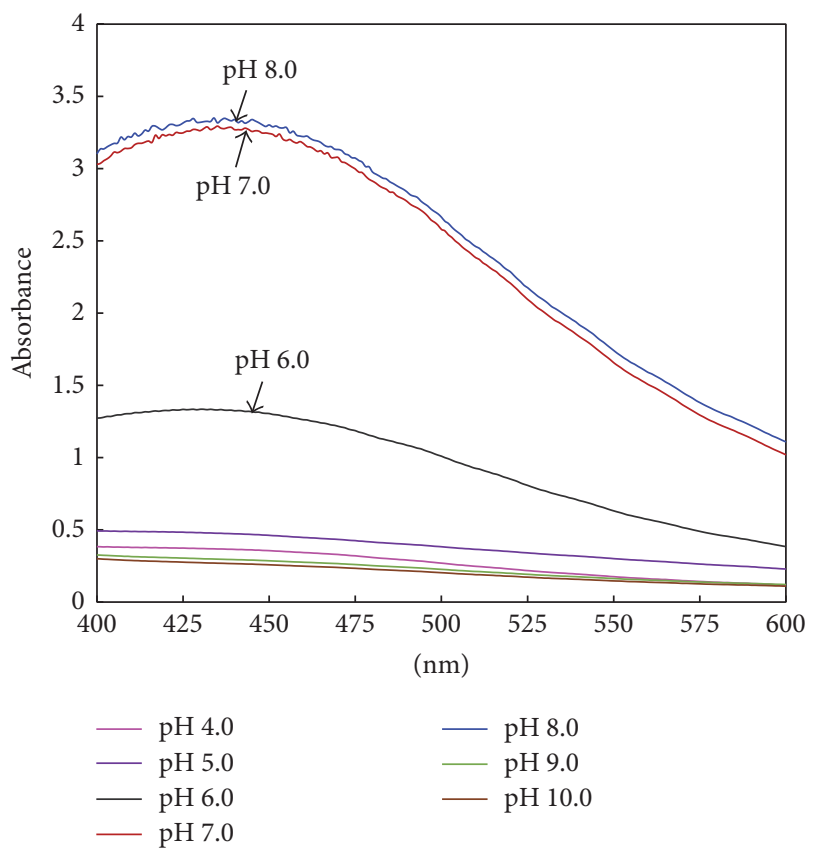

Figure 2: The effect of $\mathrm{pH}$ on AgNP synthesis.

at different temperature $\left(70,80\right.$, and $\left.90^{\circ} \mathrm{C}\right)$. Then the UVvis absorption spectra of the said reaction mixtures were recorded at different reaction time. The results revealed that the incubation temperature played an important role in the formation of AgNPs. As shown in Figure 3(a), the AgNPs synthesis was a rapid process when the incubated temperature was over $70^{\circ} \mathrm{C}$. The formation of AgNPs was observed within $10 \mathrm{~min}$ at $70^{\circ} \mathrm{C}$. The time of AgNP formation was shortened to $5 \mathrm{~min}$ at $80^{\circ} \mathrm{C}$ (Figure 3(b)). Less than two minutes were required for AgNP synthesis when the reaction temperature was increased to $90^{\circ} \mathrm{C}$ (Figure 3(c)).

3.4. Flocculation and Reduction-Based AgNP Synthesis. Based on the aforementioned experiments of AgNP synthesis, we found that the flocculation of B4-EPS always appeared with the addition of $\mathrm{AgNO}_{3}$ solution and the flocs disappeared until the reaction mixture was heated to above $70^{\circ} \mathrm{C}$, which resulted in the formation of AgNPs. To explain this phenomenon, zeta potential of B4-EPS solution before and after the addition of $\mathrm{AgNO}_{3}$ solution, the said mixtures after heating at $80^{\circ} \mathrm{C}$ for $5 \mathrm{~min}$, and the resulting $\mathrm{AgNPs} / \mathrm{B} 4$ EPS colloid solution stored at $4^{\circ} \mathrm{C}$ for one month were monitored within $10 \mathrm{~min}$ (Figure $4(\mathrm{a})$ ). Zeta potential is closely related to the surface charge of colloidal particles, and it also provides an indication of the stability of colloidal systems, which was able to be used to investigate flocculation process and nanoparticle stability [31]. The formation of AgNPs was determined via color change of reaction solution and nanoparticle images by HrTEM (Figure 4(b)). As shown in Figure 4(a), a significant increase trend in the absolute values of zeta potential revealed the flocculation of B4-EPS after the addition of $\mathrm{AgNO}_{3}$. In fact, B4-EPS had capability of flocculation and reduction under certain conditions due to its large numbers of carboxyl and hydroxyl groups according to our previous study $[23,24]$. But the oxidation of silver ions has not been observed below $60^{\circ} \mathrm{C}$ until $72 \mathrm{~h}$, which may be due to lacking of activation energy of reduction reaction or hindrance of aggregation structure or silver ion block of carboxyl and hydroxyl groups. When the temperature increased more than $70^{\circ} \mathrm{C}$, the disaggregation of flocs suggested that the high activation energy and exposed carboxyl 


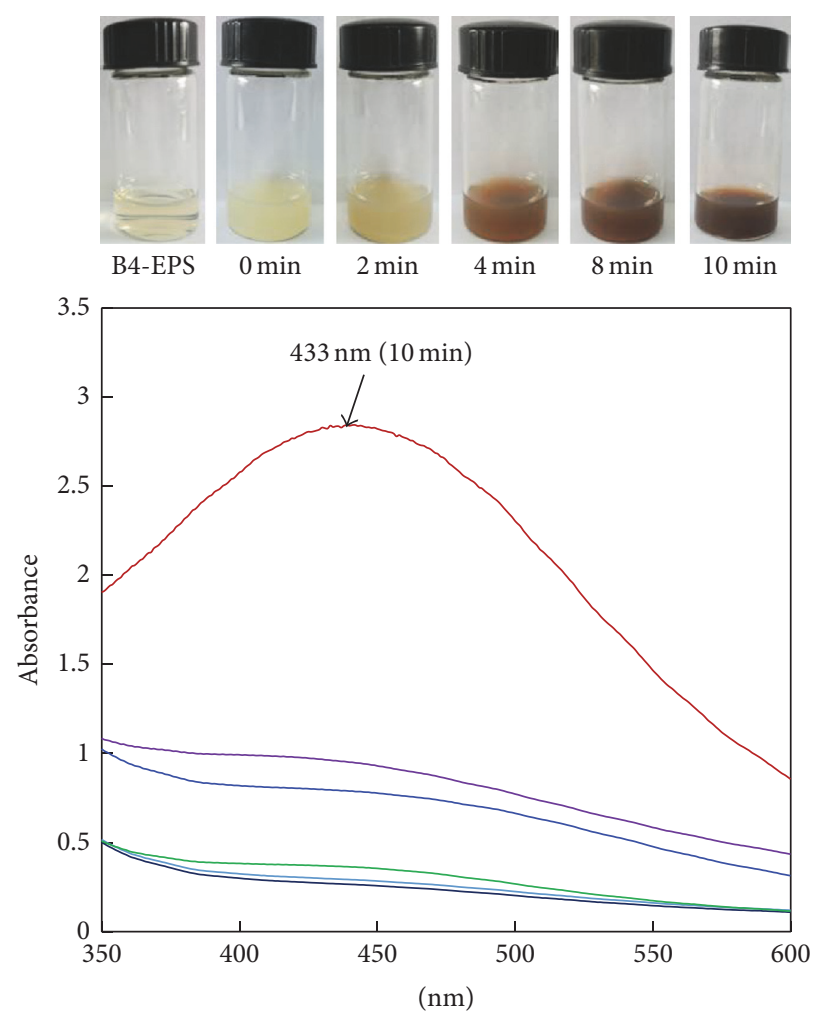

$\left(70^{\circ} \mathrm{C}\right)$

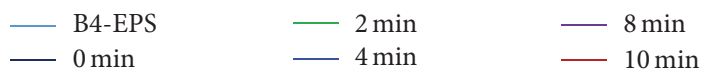

(a)
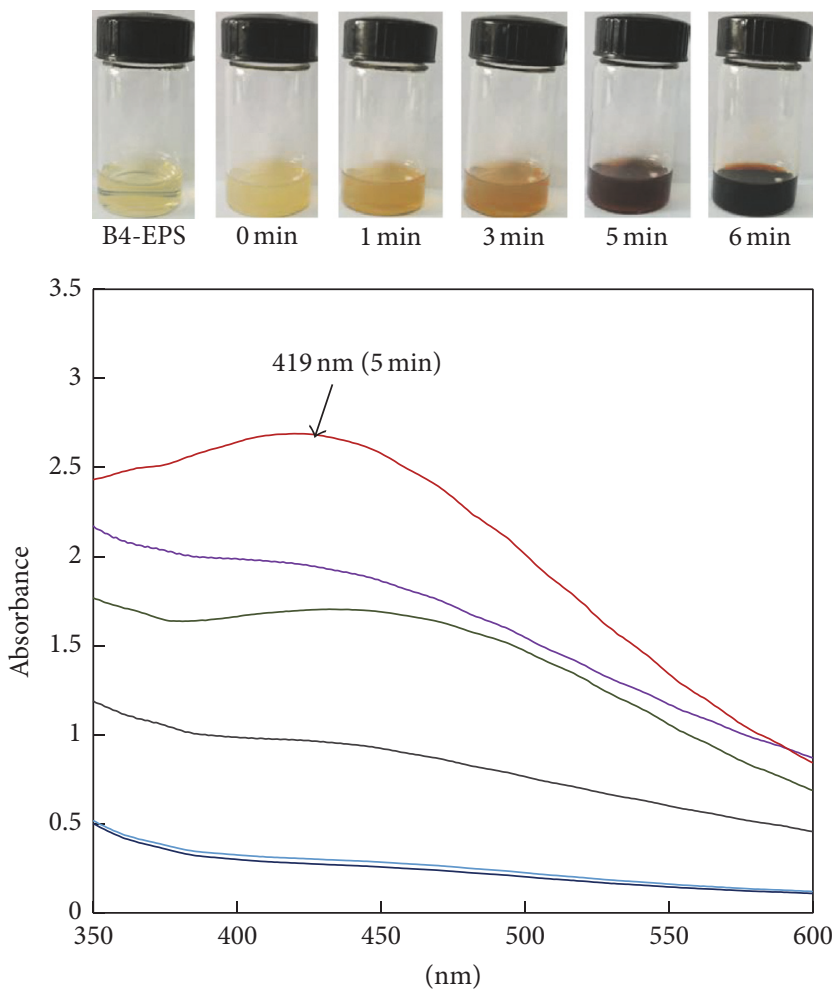

$\left(80^{\circ} \mathrm{C}\right)$

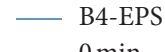

$-1 \mathrm{~min}$

(b)
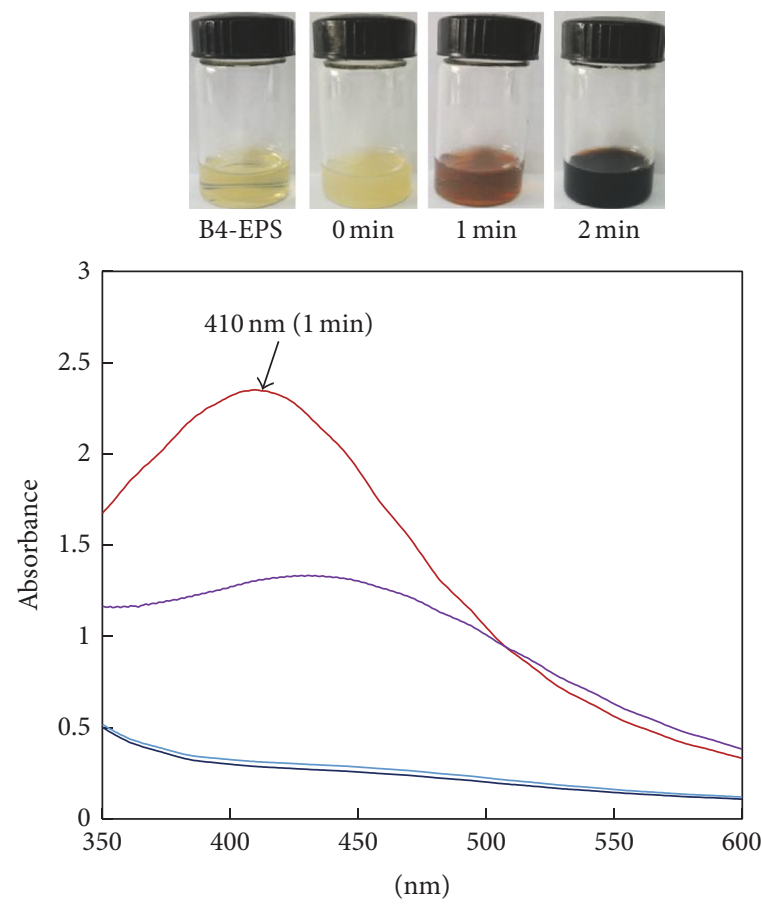

$\left(90^{\circ} \mathrm{C}\right)$

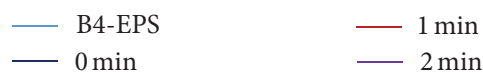

(c)

FIGURE 3: The effects of temperature and heating time on AgNP synthesis. AgNP synthesis were performed at $70^{\circ} \mathrm{C}$ for $10 \mathrm{~min}(\mathrm{a}), 80^{\circ} \mathrm{C}$ for $6 \mathrm{~min}(\mathrm{~b})$, and $90^{\circ} \mathrm{C}$ for $2 \mathrm{~min}$ (c), respectively. 


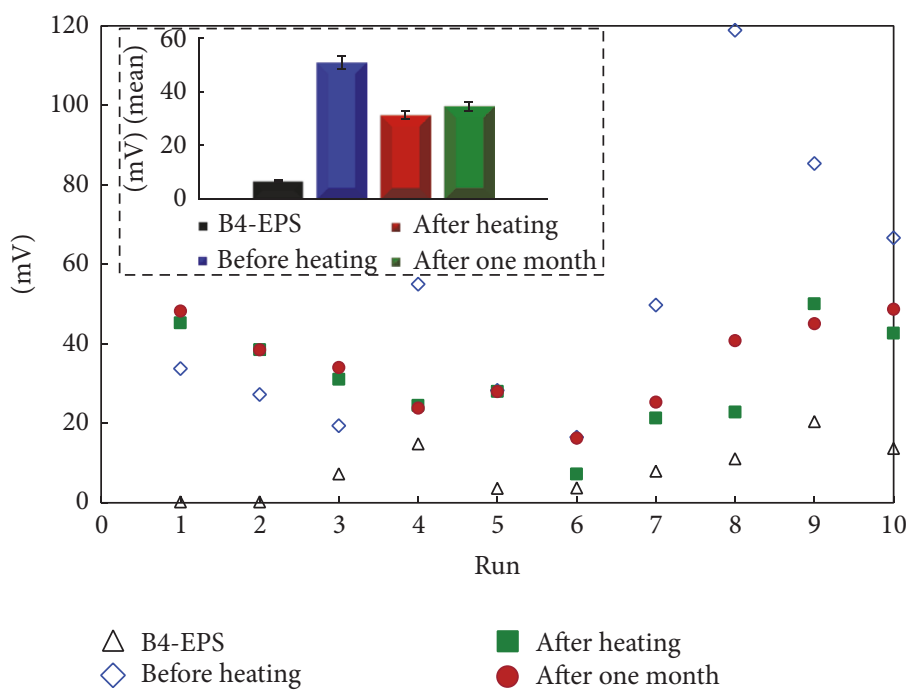

(a)

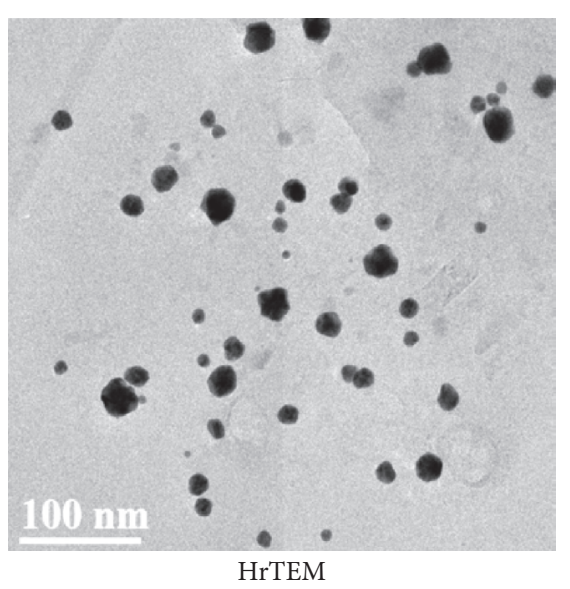

(c)
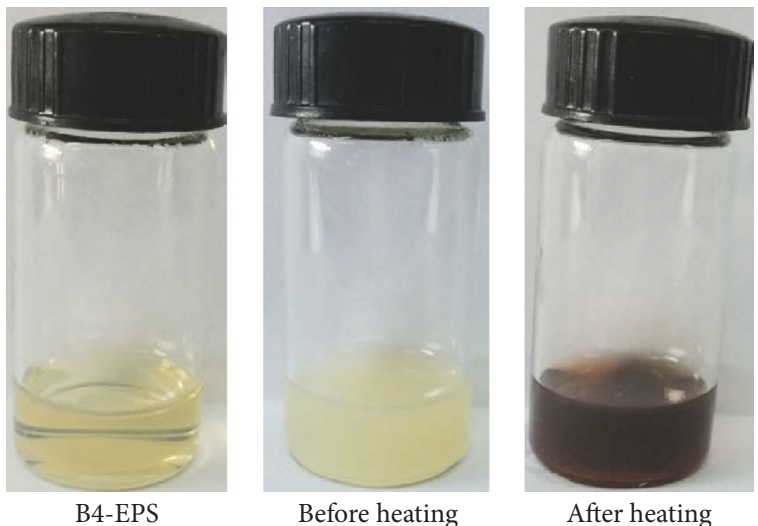

(b)

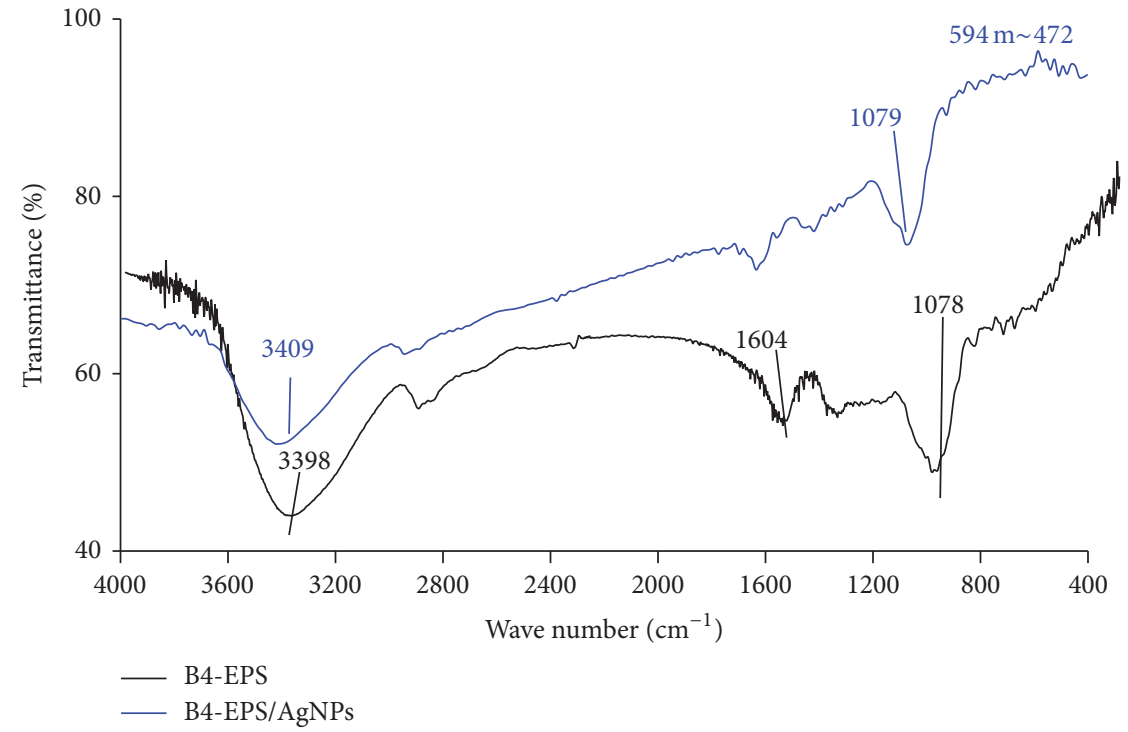

(d)

Figure 4: Analysis of AgNP synthesis. Zeta potential before and after the formation of AgNPs (a); the color change of reaction solutions in the process of AgNP synthesis (b); observation of nanoparticle formation by HrTEM (c); FTIR of B4-EPS and B4-EPS/AgNPs (d).

and hydroxyl groups endowed B4-EPS enough reduction ability in favor of AgNP synthesis and the aggregation of AgNPs was prevented owing to binding polysaccharide chain with high electronegativity, whose good dispersion was demonstrated by a stable zeta potential $(>30 \mathrm{mV})$ after onemonth storage at $4^{\circ} \mathrm{C}$ (Figure 4(a)). Furthermore, the FTIR spectral analysis revealed the presence of the main absorption peaks at 3098,1604 , and $1078 \mathrm{~cm}^{-1}$ due to $\mathrm{O}-\mathrm{H}$ stretching, $\mathrm{C}-\mathrm{H}$ stretching, and $\mathrm{C}=\mathrm{O}$ stretching (Figure $4(\mathrm{c})$ ). The shift of $-\mathrm{C}=\mathrm{O}$ and $-\mathrm{OH}$ absorption peaks before and after the formation of AgNPs confirmed that B4-EPS was responsible for reducing $\mathrm{Ag}^{+}$ion and leading to high stabilization of AgNPs as capping agents. Moreover, the absorption peaks between 472 and $594 \mathrm{~cm}^{-1}$ indicated the presence of $\mathrm{Ag}-\mathrm{O}$ van der Waal interactions [32], which was not observed at positions in the B4-EPS spectrum. In terms of the said results, a tentative reaction model was proposed to describe flocculation and reduction-based AgNPs synthesis by B4EPS. Firstly, the -COOH groups of B4-EPS were easily ionized as $-\mathrm{COO}^{-}$in alkaline condition; the flocculation of B4-EPS was observed after addition to $\mathrm{AgNO}_{3}$ solution due to charge attraction between $-\mathrm{COO}^{-}$and $\mathrm{Ag}^{+}$ions, which was able to urge $\mathrm{Ag}^{+}$ions close to the reduction groups (carboxyl and hydroxyl groups) of B4-EPS. Secondly, the oxidation of $\mathrm{Ag}^{+}$ions occurred when the incubated temperature was increased to $80^{\circ} \mathrm{C}$ due to enough activation energy from heating in favor of AgNPs synthesis. Then B4-EPS as capping agents could keep good stability of the synthesized AgNPs. 


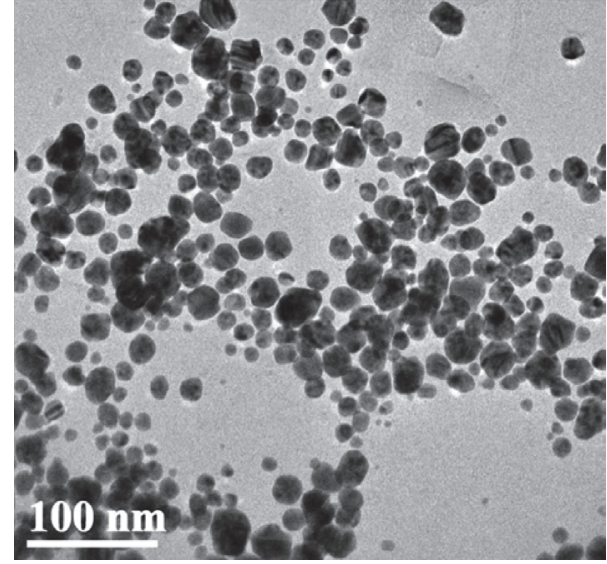

(a)

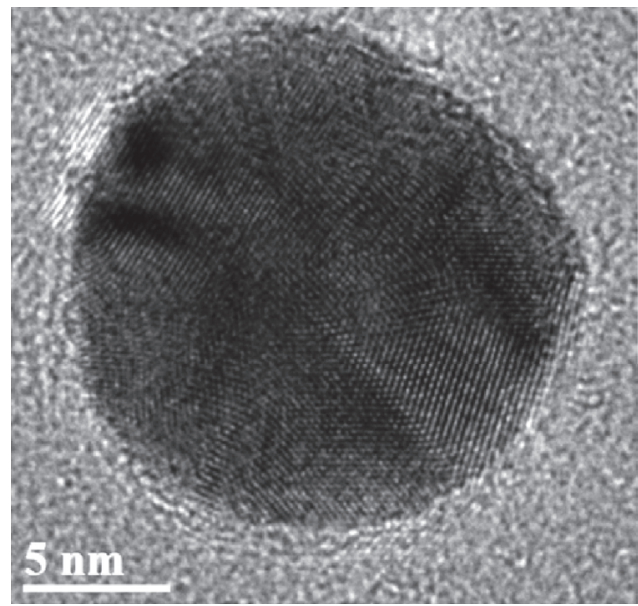

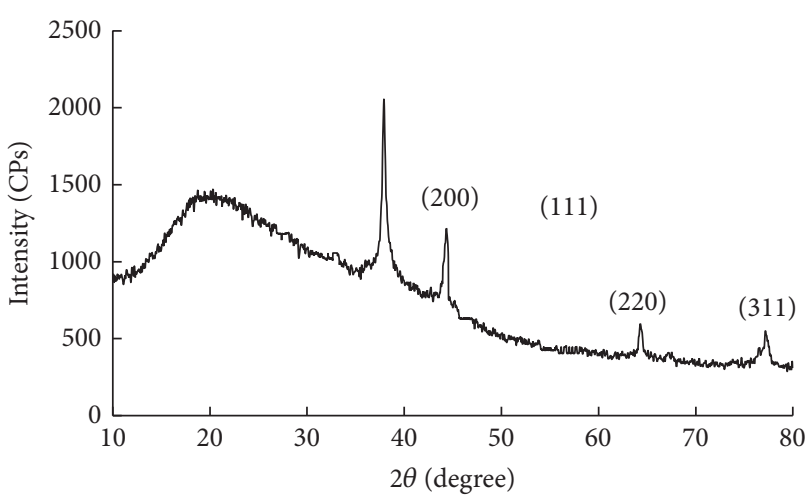

(d)

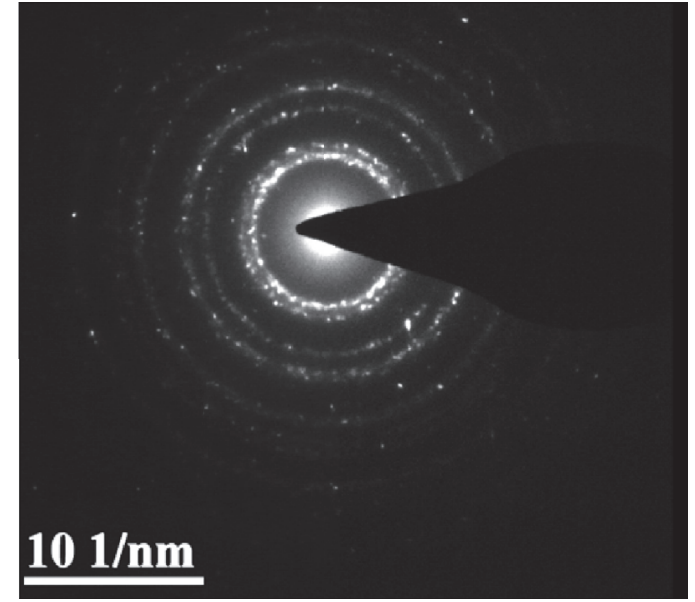

(c)

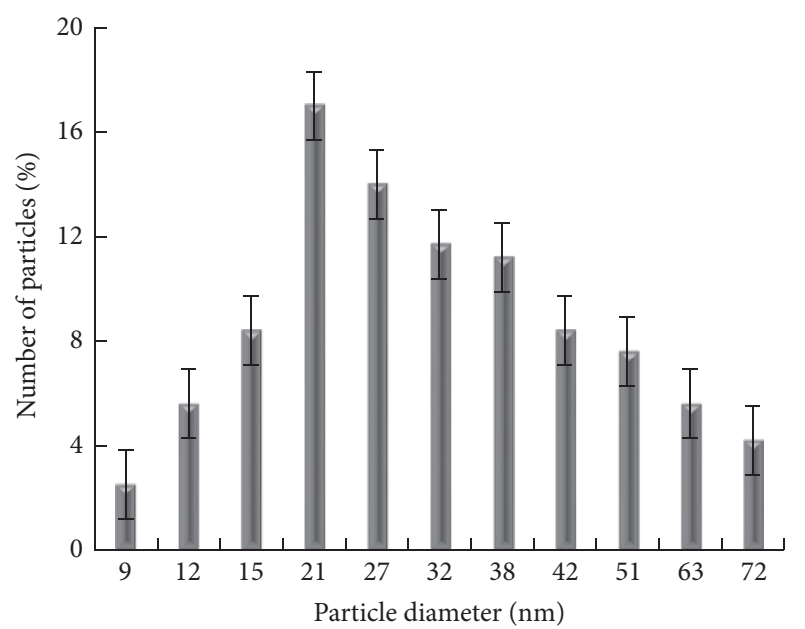

(b)

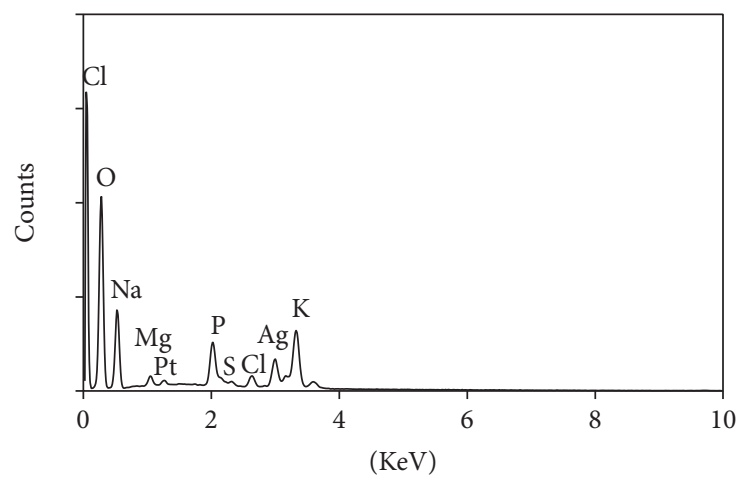

(e)

FIGURE 5: Characterization of AgNPs. Characterization of AgNPs by HrTEM (a); frequency of particle size distribution (b); SAED patterns (c); XRD analysis of AgNPs (d); EDS profiles of AgNPs (e).

3.5. Characterization of AgNPs. The morphology of AgNPs was determined by recording HrTEM images (Figure 5(a)) and particle size distribution was calculated by Image $\mathrm{J}$ software (http://imagej.net/Welcome) according to HrTEM images. As shown in Figure 5(a), the formed nanoparticles were typically spherical with a particle diameter size in the range of 9-72 nm (Figure 5(b)). Furthermore, SAED patterns of the single particle revealed a characteristic polycrystalline ring pattern for a face-centred-cubic structure (Figure 5(c)). Also, XRD pattern of AgNPs revealed four distinctive diffraction peaks at $38.2,44.3,64.4$, and 77.5 in the 2 theta region, which corresponded to (111), (200), (220), and (311) planes 


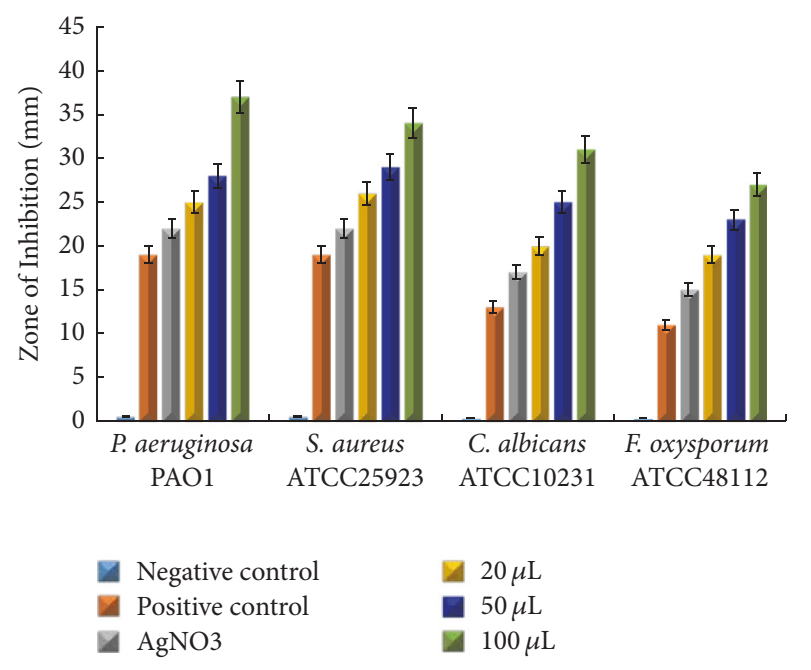

Figure 6: Antimicrobial activity assay of AgNPs.

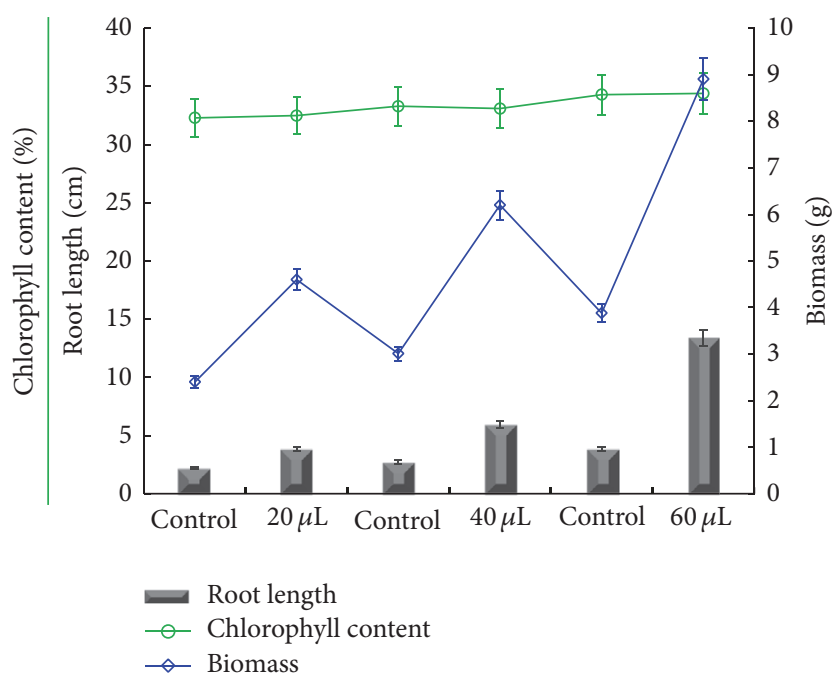

FIgURe 7: Phytotoxicity assay of AgNPs.

of silver (Figure 5(d)). The EDS spectrum confirmed the presence of silver element (Figure 5(e)).

3.6. Antimicrobial Activity of AgNPs. The AgNPs showed strong antimicrobial activity against the tested pathogen strains. As shown in Figure 6, the zones of inhibition for the aforementioned strains in the presence of different concentration of AgNPs were found to be bigger than that of positive control and the same concentration of $\mathrm{AgNO}_{3}$, while the negative control (B4-EPS and distilled water) shows no any antimicrobial activity. The antimicrobial ability of AgNPs showed a dose-dependent manner.

3.7. Phytotoxicity of AgNPs. The AgNPs exhibited different responses to seed germination, root length, and chlorophyll content of the tested alfalfa (Figure 7). No significant effect on seed germination was observed in the presence of different dose of AgNPs. In the root length test, $\mathrm{AgNP}_{3}$ made no difference to root growth at a lower concentration, while it promoted root growth at a middle concentration. An obvious growth inhibition occurred at a higher concentration, which was in agreement with previous study that a concentration dependent growth inhibition was observed in other plants by AgNPs [20]. In addition, the chlorophyll content of the tested alfalfa was in accordance with the control.

\section{Conclusions}

In this study, a simple and rapid eco-friendly approach for the synthesis of AgNPs was presented. The optimum conditions for the formation of AgNPs were found to be $5 \mathrm{~g} / \mathrm{L}$ B4-EPS and $1 \mathrm{mM} \mathrm{AgNO}_{3}$ at a high temperature $\left(70-90^{\circ} \mathrm{C}\right)$ under low alkaline conditions ( $\mathrm{pH}$ 7.0-8.0). Subsequent zeta potential and FTIR analysis revealed flocculation and reduction of B4EPS contributing to AgNPs synthesis. The resulting AgNPs with size range of 9-72 $\mathrm{nm}$ were very stable due to the strong electrostatic interaction between B4-EPS and AgNPs. Furthermore, the said AgNPs exhibited excellent antimicrobial ability and low phytotoxicity. These data suggested that these AgNPs had a great application potential in many fields.

\section{Conflicts of Interest}

The authors declare that they have no conflicts of interest.

\section{Acknowledgments}

Thanks are due to the financial support provided by National Natural Science Foundation of China (Projects nos. 31300045 and 41506148), Key research and development program of Shandong Province (2016GSF121018), Shandong Excellent Young Scientist Award Fund (BS2015HZ005), A Project of Shandong Province Higher Educational Science and Technology Program (YE13), and Foundation of University of Jinan (XKY1324, XBS1422).

\section{References}

[1] W. Ho, Y. Lee, C. Hu, and W. Wang, "Electrical and optical performance of plasmonic silicon solar cells based on light scattering of silver and indium nanoparticles in matrixcombination," Optics Express, vol. 24, no. 16, pp. 17900-17909, 2016.

[2] R. Manikandan, B. Manikandan, T. Raman et al., "Biosynthesis of silver nanoparticles using ethanolic petals extract of Rosa indica and characterization of its antibacterial, anticancer and anti-inflammatory activities," Spectrochimica Acta. Part A: Molecular and Biomolecular Spectroscopy, vol. 138, pp. 120-129, 2015.

[3] B. Wiley, Y. Sun, B. Mayers, and Y. Xia, "Shape-controlled synthesis of metal nanostructures: the case of silver," Chemistry, vol. 11, no. 2, pp. 454-463, 2005.

[4] D. D. Evanoff Jr. and G. Chumanov, "Size-controlled synthesis of nanoparticles. 2. Measurement of extinction, scattering, and absorption cross sections," Journal of Physical Chemistry B, vol. 108, no. 37, pp. 13957-13962, 2004.

[5] G. Merga, R. Wilson, G. Lynn, B. H. Milosavljevic, and D. Meisel, "Redox catalysis on "naked" silver nanoparticles," Journal of Physical Chemistry C, vol. 111, no. 33, pp. 12220-12226, 2007. 
[6] S. I. Dolgaev, A. V. Simakin, V. V. Voronov, G. A. Shafeev, and F. Bozon-Verduraz, "Nanoparticles produced by laser ablation of solids in liquid environment," Applied Surface Science, vol. 186, no. 1-4, pp. 546-551, 2002.

[7] S. C. Hamm, R. Shankaran, V. Korampally et al., "Sputterdeposition of silver nanoparticles into ionic liquid as a sacrificial reservoir in antimicrobial organosilicate nanocomposite coatings," ACS Applied Materials and Interfaces, vol. 4, no. 1, pp. 178-184, 2012.

[8] C.-M. Chen, Y.-J. Huang, and K.-H. Wei, "Structural development of gold and silver nanoparticles within hexagonally ordered spherical micellar diblock copolymer thin films," Nanoscale, vol. 6, no. 11, pp. 5999-6008, 2014.

[9] X. Guo, Y. Li, J. Yan et al., "Size- and coating-dependent cytotoxicity and genotoxicity of silver nanoparticles evaluated using in vitro standard assays," Nanotoxicology, vol. 10, no. 9, pp. 1373-1384, 2016.

[10] N. I. Hulkoti and T. Taranath, "Biosynthesis of nanoparticles using microbes-a review," Colloids and Surfaces B: Biointerfaces, vol. 121, pp. 474-483, 2014.

[11] G. Benelli, "Plant-mediated biosynthesis of nanoparticles as an emerging tool against mosquitoes of medical and veterinary importance: a review," Parasitology Research, vol. 115, no. 1, pp. 23-34, 2016.

[12] H. Wennemers, "Peptides as asymmetric catalysts and templates for the controlled formation of Ag nanoparticles," Journal of Peptide Science, vol. 18, no. 7, pp. 437-441, 2012.

[13] J. Wang, H. Chen, Z. Chen et al., "In-situ formation of silver nanoparticles on poly (lactic acid) film by $\gamma$-radiation induced grafting of N-vinyl pyrrolidone," Materials Science and Engineering: C, vol. 63, pp. 142-149, 2016.

[14] J. Yan, A. M. Abdelgawad, M. E. El-Naggar, and O. J. Rojas, "Antibacterial activity of silver nanoparticles synthesized In-situ by solution spraying onto cellulose," Carbohydrate Polymers, vol. 147, pp. 500-508, 2016.

[15] S. M. Alshehri, T. Almuqati, N. Almuqati, E. Al-Farraj, N. Alhokbany, and T. Ahamad, "Chitosan based polymer matrix with silver nanoparticles decorated multiwalled carbon nanotubes for catalytic reduction of 4-nitrophenol," Carbohydrate Polymers, vol. 151, pp. 135-143, 2016.

[16] A. Hebeish, T. I. Shaheen, and M. E. El-Naggar, "Solid state synthesis of starch-capped silver nanoparticles," International Journal of Biological Macromolecules, vol. 87, pp. 70-76, 2016.

[17] D. Breitwieser, S. Spirk, H. Fasl et al., "Design of simultaneous antimicrobial and anticoagulant surfaces based on nanoparticles and polysaccharides," Journal of Materials Chemistry B, vol. 1, no. 15, pp. 2022-2030, 2013.

[18] D. Breitwieser, M. M. Moghaddam, S. Spirk et al., "In situ preparation of silver nanocomposites on cellulosic fibersmicrowave vs. conventional heating," Carbohydrate Polymers, vol. 94, no. 1, pp. 677-686, 2013.

[19] S. Dhar, P. Murawala, A. Shiras, V. Pokharkar, and B. L. V. Prasad, "Gellan gum capped silver nanoparticle dispersions and hydrogels: cytotoxicity and in vitro diffusion studies," Nanoscale, vol. 4, no. 2, pp. 563-567, 2012.

[20] S. Coseri, A. Spatareanu, L. Sacarescu et al., "Green synthesis of the silver nanoparticles mediated by pullulan and 6carboxypullulan," Carbohydrate Polymers, vol. 116, pp. 9-17, 2015.

[21] G. Sathiyanarayanan, G. Seghal Kiran, and J. Selvin, "Synthesis of silver nanoparticles by polysaccharide bioflocculant produced from marine Bacillus subtilis MSBN17," Colloids and Surfaces B: Biointerfaces, vol. 102, pp. 13-20, 2013.

[22] P. Manivasagan, K. Kang, D. G. Kim, and S. Kim, "Production of polysaccharide-based bioflocculant for the synthesis of silver nanoparticles by Streptomyces sp," International Journal of Biological Macromolecules, vol. 77, pp. 159-167, 2015.

[23] Y. Li, Q. Li, D. Hao, Z. Hu, D. Song, and M. Yang, "Characterization and flocculation mechanism of an alkali-activated polysaccharide flocculant from Arthrobacter sp. B4," Bioresource Technology, vol. 170, pp. 574-577, 2014.

[24] Y. Li, Q. Li, F. Yang et al., "Chromium (VI) detoxification by oxidation and flocculation of exopolysaccharides from Arthrobacter sp. B4," International Journal of Biological Macromolecules, vol. 81, pp. 235-240, 2015.

[25] Y. Zhao, Y. Jiang, and Y. Fang, "Spectroscopy property of Ag nanoparticles," Spectrochimica Acta Part A: Molecular and Biomolecular Spectroscopy, vol. 65, no. 5, pp. 1003-1006, 2006.

[26] W. Obonga, C. Nnadi, M. Agbo, F. Kenechukwu, and U. Nwodo, "Distribution of Methicillin-Resistant Staphylococcus aureus (MRSA) in apparently healthy population and its susceptibility to Saponins from Dialium guineense," British Journal of Pharmaceutical Research, vol. 4, no. 18, pp. 2200-2209, 2014.

[27] A. U. Turker and N. D. Camper, "Biological activity of common mullein, a medicinal plant," Journal of Ethnopharmacology, vol. 82, no. 2-3, pp. 117-125, 2002.

[28] P. P. Bettini, M. Marvasi, F. Fani et al., "Agrobacterium rhizogenes rolB gene affects photosynthesis and chlorophyll content in transgenic tomato (Solanum lycopersicum L.) plants," Journal of Plant Physiology, vol. 204, pp. 27-35, 2016.

[29] R. F. Elsupikhe, K. Shameli, M. B. Ahmad, N. A. Ibrahim, and N. Zainudin, "Green sonochemical synthesis of silver nanoparticles at varying concentrations of $\kappa$-carrageenan," Nanoscale Research Letters, vol. 10, no. 1, article 302, 2015.

[30] F. Iram, M. S. Iqbal, M. M. Athar, M. Z. Saeed, A. Yasmeen, and R. Ahmad, "Glucoxylan-mediated green synthesis of gold and silver nanoparticles and their phyto-toxicity study," Carbohydrate Polymers, vol. 104, no. 1, pp. 29-33, 2014.

[31] N. Spanos, P. G. Klepetsanis, and P. G. Koutsoukos, Encyclopedia of Surface and Colloid Science, Marcel Dekker, New York, NY, USA, 2002.

[32] M. A. Hussain, A. Shah, I. Jantan et al., "Hydroxypropylcellulose as a novel green reservoir for the synthesis, stabilization, and storage of silver nanoparticles," International Journal of Nanomedicine, vol. 10, pp. 2079-2088, 2015. 

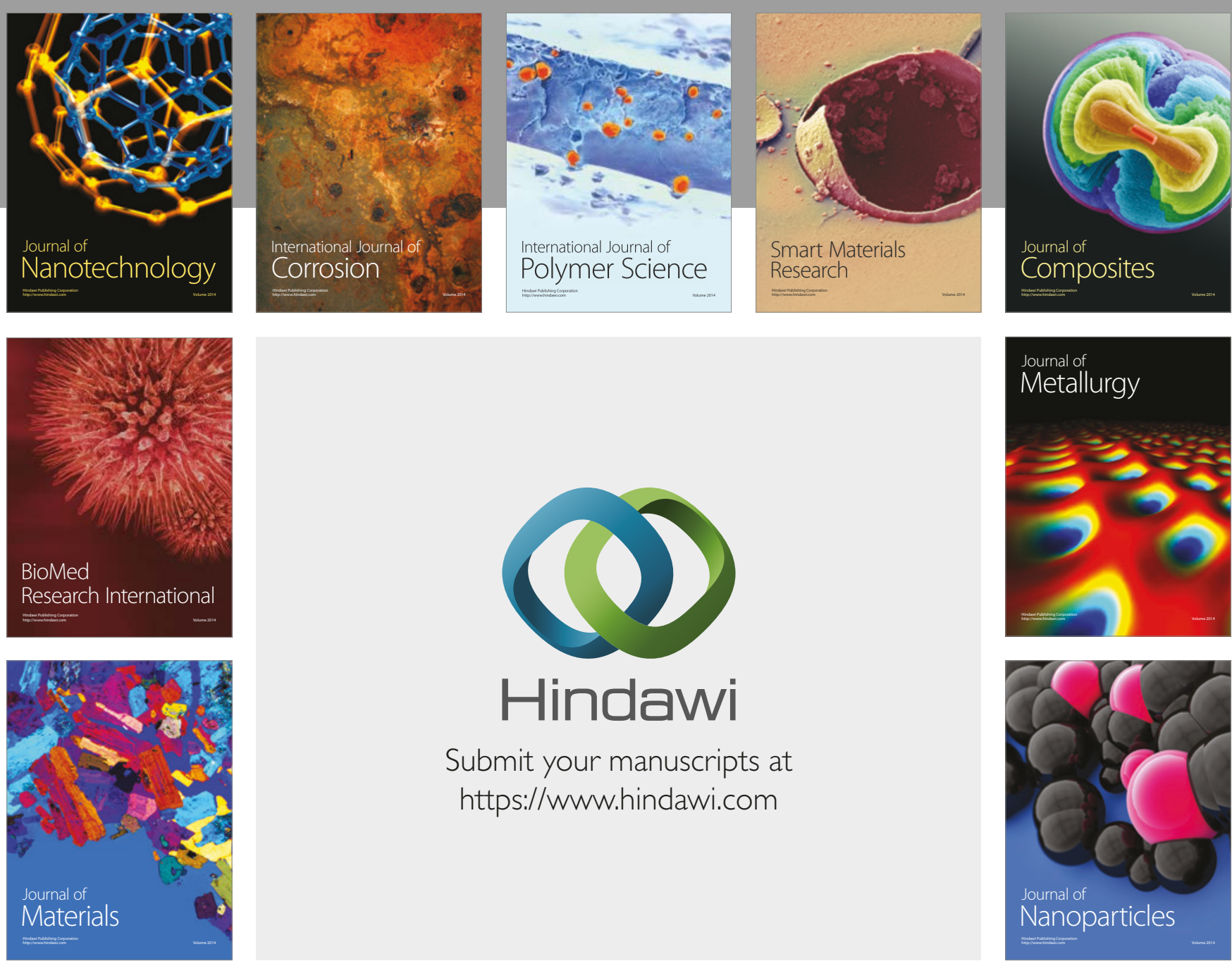

\section{Hindawi}

Submit your manuscripts at

https://www.hindawi.com
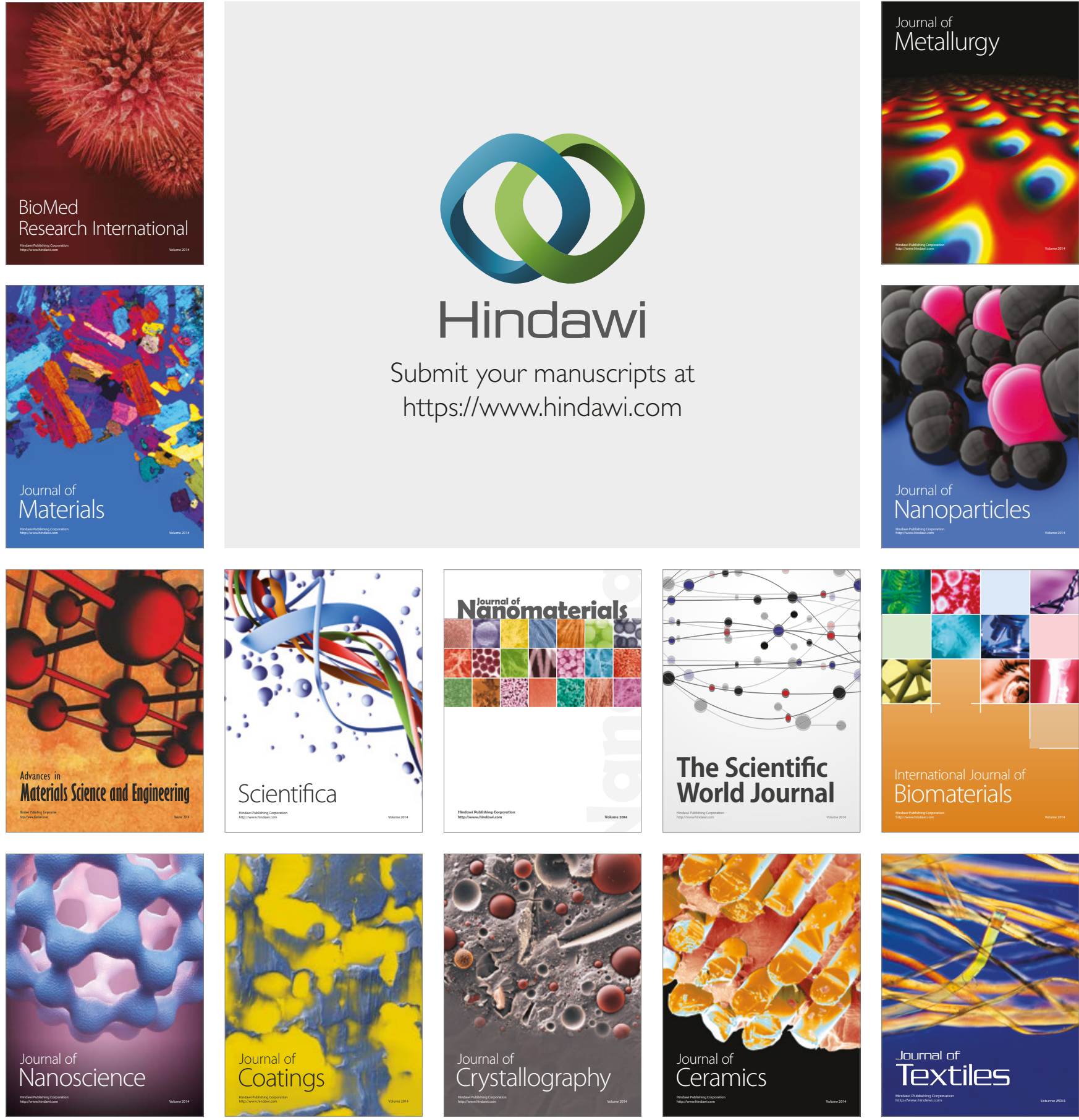

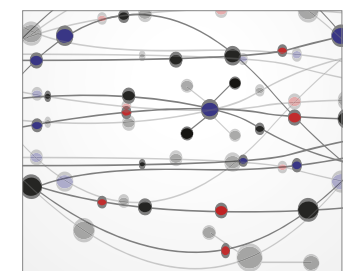

The Scientific World Journal
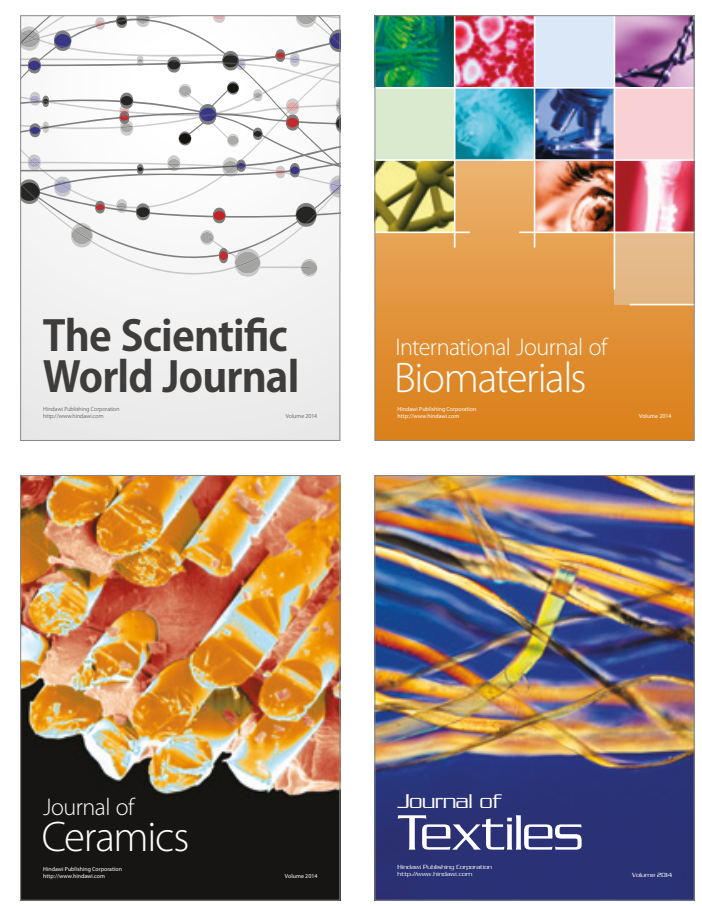